\title{
Utilization plasters with superabsorbent admixture to moderate moisture level in constructions
}

\author{
Jan Fořt ${ }^{1, *}$, Petr Hotěk ${ }^{1}$, Jan Kočí ${ }^{1}$ and Robert Černý $^{1}$ \\ ${ }^{1}$ Department of Materials Engineering and Chemistry, Faculty of Civil Engineering, Czech Technical University in Prague, Thákurova 7 , \\ Prague 6, 160 00, Czech Republic
}

\begin{abstract}
The level of indoor humidity has to meet several criteria according to the preservation of a healthy indoor climate for building inhabitants. On top of that, the undesired moisture content is associated with a proliferation of various organisms which results in an adverse effect on the durability of building materials. Facing the impact of climate change and excessive energy consumption associated with building maintenance, the employment of passive moderation techniques takes place to avoid the usage of energydemanding HVAC devices. The application of advanced materials such as superabsorbent polymers (SAPs), commonly used in diapers or other hygiene products, can bring a very effective solution for this issue overcoming. In this paper, the effect of 0.5 ; 0.1 and $1.5 \mathrm{wt} . \%$ dosages of SAPs incorporated into a cementlime plaster are studied to evaluate the material performance in the sense of moisture moderation. First, the basic material properties, moisture transport and storage properties, thermal conductivity and specific heat capacity are determined to access the influence of SAP admixtures on the functional performance of studied plasters. Consequently, the experimentally accessed results are further employed for the computational modeling analysis which evaluates the capability of studied plasters for the moderation of moisture content in constructions.
\end{abstract}

\section{Introduction}

From ancient times, plasters were used predominantly as a decoration and a finishing layer for structural materials such as bricks, stones, concrete or other modern building materials [1]. Alternatively, these materials were employed as protection against the outdoor climate condition and thus prolong the service life for underlying materials. Originally, the mortars or plasters were composed of air or hydraulic lime and modified for specific purposes latterly.

In line with the development of advanced building materials, modified plasters were introduced to provide compatible material with specific characteristics relevant to specific building issues. Nowadays, we can distinguish several types of plasters having various parameters [2 - 4]. Besides the thermal performance of building envelopes, the moisture content in building materials has attracted particular attention within the last decades. Such a phenomenon has a close relation to interior relative humidity which became an important issue for the preservation of sufficient quality of indoor air [4]. Apart from that, the excessive moisture content in finishing layers negatively affects the durability of materials and shortens the service life of furnishing [3]. Moisture-related problems can be distinguished predominantly in old masonries, notwithstanding, modern airtight building envelopes suffer from limited moisture evaporation. Considering the recent knowledge, the level of moisture content is accompanied by health risk for building occupants due to correlation with indoor relative humidity $[2,5]$. Specifically, since the people spend in building interiors a significant part of the day, health problems such as allergic rhinitis, eye or skin irritation, eczema, asthma, coughing, and wheezing can be expected in case of unsatisfactory indoor air quality $[6,7]$. Present literature calls these issues as the Sick Building Syndrome or Building Related Illness [6]. Apart from the potential health problems, the excessive moisture level has a significant impact on operational energy $[3,8]$. On this account, the regulation of moisture poses a very important issue for building engineers. Most often, additional HVAC devices are employed, however, this approach does not meet the criteria paid on low energy consumption, and such systems require significant financial assets. Therefore, indoor air quality control needs to be secured by passive systems by utilization of the hygroscopic capability of used building materials $[5,7$ - 10].

In light of the aforementioned issues, the application of lightweight aggregates was studied as one of the easiest ways to improve the hygroscopicity of finishing materials. Notwithstanding, the incorporation of vermiculite, sepiolite, cellulose, perlite, and other bulk materials was revealed as only minor improvements to increase the absorption capacity of modified plasters

* Corresponding author: jan.fort@,fsv.cvut.cz 
[11]. Moreover, some drawbacks as loss of workability and strength impose a limitation of such modifications. Another viable way employed for improvement in the water vapor absorptivity can be delivered by the driven modulation of a material porosity including the size and shape distribution. For this purpose, Goncalves et al. [12] utilized porogene additives such as aluminum powder and sodium olefin-sulphonate for modification of mortars porosity. However, achieved results gained only a limited effect on the material moisture buffering compared to original materials. In recent years, increased attention was paid to the application of advanced responsive materials such as phase change materials or superabsorbent polymers (SAPs), which demonstrates the relevance of this theme. Namely, SAPs have been effectively utilized for the reduction of the concrete shrinkage and improved internal curing of fresh mixtures. Alternatively, a few authors considered SAPs as a passive alternative for the moisture control which can deliver substantial improvements in terms of modification of moisture transport properties. Compared to advancements provided by porogene additives or lightweight aggregates, incorporation of SAPs maintains significantly improved performance in the sense of the passive moisture moderation [13]. However, the robust evaluation or comparison still missing due to the barrier formed by reduced workability and durability of plasters mixtures modified by SAPs.

In this paper, we performed the computational simulation based on the experimentally accessed parameters of newly developed plasters enhanced by SAP admixture. Firstly, the basic physical, thermal and moisture properties were obtained and consequently used as input parameters for computational analysis. The main scope of this study was aimed at the determination of the hygrothermal performance of modified plasters and their contribution to the preservation of the moisture content in building materials. Based on the revealed results, SAPs incorporation can be viewed as beneficial from the hygrothermal performance.

\section{Experimental}

\subsection{Studied materials}

In this study, the investigation and computational modeling of hygrothermal performance of modified plasters by SAPs were done on the brick wall assembly consisted of brick wall (450 mm thickness), exterior plaster and interior plaster modified by various SAP admixture as specified below. Interior plaster contained various amounts of SAP (Creasorb produced by Evonik Ltd., Germany) and were marked as PR, P0.5, P1, and P1.5. According to data provided by the producer, the used SAP (see Fig. 1) is a low-crosslinking sodium acrylate which is able to absorb about $80 \mathrm{~g}$ of distilled water per 1 gram with the powder density of about 600 $\mathrm{kg} / \mathrm{m}^{3}$.

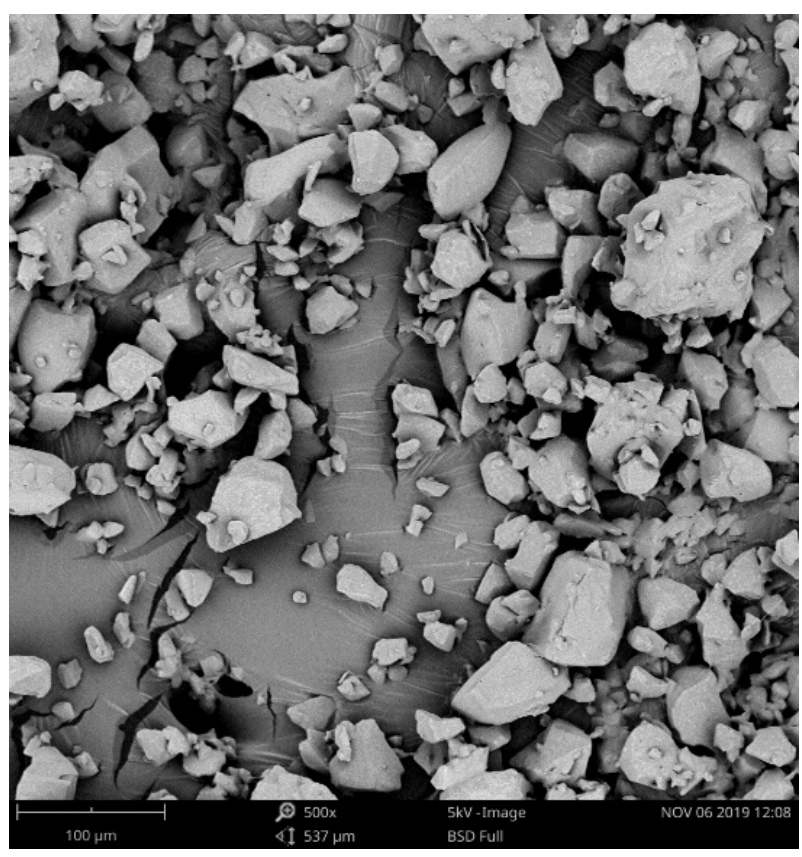

Fig. 1. SEM image of used SAP

PR refers to the reference plaster, specifically MV1 (Knauf, Germany) without any modification and prepared accordingly to the product sheet provided by the producer. The studied wall cross-section is given in Fig. 2.

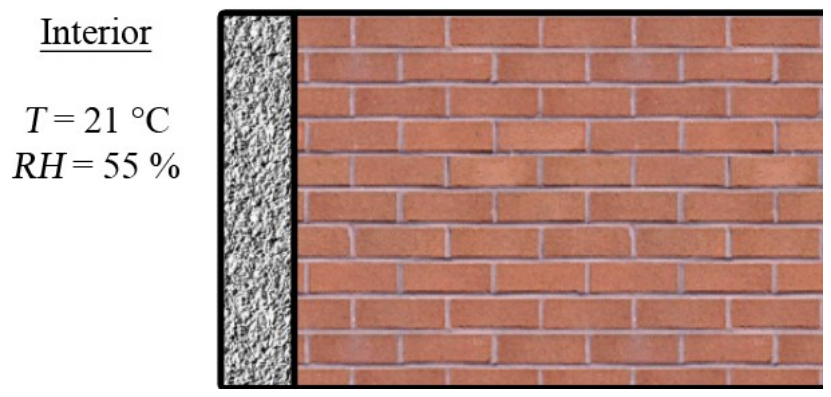

Fig. 2. Tested wall assembly

\subsection{Experimental methods}

Firstly, the basic physical, mechanical, hygric, and thermal characteristics of modified plasters were determined.

The bulk density $\rho_{v}\left(\mathrm{~kg} \cdot \mathrm{m}^{-3}\right)$ was determined using the dimensions and weight of the dry samples. Matrix density $\rho_{\text {mat }}\left(\mathrm{kg} \cdot \mathrm{m}^{-3}\right)$ and open porosity $\Psi\left(\mathrm{m}^{3} \cdot \mathrm{m}^{-3}\right)$ were estimated using the helium pycnometry by the help of Pycnomatic ATC (Thermo Scientific) device. The open porosity $\Psi$ was calculated from known masses of dry sample $m_{\mathrm{d}}(\mathrm{kg})$ and saturated sample $m_{\mathrm{w}}(\mathrm{kg})$ as

$$
\psi=\frac{m_{w}-m_{d}}{V \rho_{w}},
$$

where $V\left(\mathrm{~m}^{3}\right)$ is the sample volume and $\rho_{w}\left(\mathrm{~kg} \cdot \mathrm{m}^{-3}\right)$ is the density of water. The matrix density $\rho_{\text {mat }}$ was calculated according to the following formula 


$$
\rho_{\text {mat }}=\frac{m_{d}}{(1-\psi) V} \text {. }
$$

Thermal conductivity $\lambda\left(\mathrm{W} \cdot \mathrm{m}^{-1} \cdot \mathrm{K}^{-1}\right)$ and specific heat capacity $c\left(\mathrm{~J} \cdot \mathrm{kg}^{-1} \cdot \mathrm{K}^{-1}\right)$ were measured using the commercial device Isomet 2114 (Applied Precision, Ltd.). Isomet 2114 was equipped with surface probes suitable for the measurement of building materials. The measurement principle is based on the analysis of the temperature response of the studied material to heat flow impulses. The heat flow is driven by electrical heating using a resistor heater having direct thermal contact with the sample surface. The measurements of thermal conductivity and specific heat capacity were done for dry state only. The values for wet states were calculated using mixing formulas.

The water vapor diffusion resistance factor $\mu(-)$ was determined by the help of the cup method at $21^{\circ} \mathrm{C}$. The measurement was based on 1-D water vapor transmission through a sample [14]. The diffusion water vapor flux was induced by a difference between partial pressure of water vapor of the air below and above measured sample surface. Both, the water vapor flux and partial pressures were monitored during the experiment. Within the measuring period, only one setup was of modification of water vapor transport properties. In this setup, the upper and lower environment, i.e. above and below the sample, as defined by $5 \%$ and $50 \%$ of relative humidity, respectively. Consequently, the water vapor diffusion permeability $\delta(\mathrm{s})$ was obtained from measured data according to the equation

$$
\delta=\frac{\Delta m \cdot d}{S \cdot \tau \cdot \Delta p_{p}}
$$

where $\Delta m(\mathrm{~kg})$ is the amount of water vapor diffused through the sample, $d(\mathrm{~m})$ the sample thickness, $S\left(\mathrm{~m}^{2}\right)$ the specimen surface, $\tau(\mathrm{s})$ the period of time-related to the transport of mass of water vapor $\Delta m$, and $\Delta p_{\mathrm{p}}(\mathrm{Pa})$ the difference between partial water vapor pressure in the air under and above specific specimen surface. Once $\delta$ is calculated, the other parameters, namely the water vapor diffusion coefficient $D\left(\mathrm{~m}^{2} \cdot \mathrm{s}^{-1}\right)$ and water vapor diffusion resistance factor $\mu(-)$, can be calculated as

$$
\begin{gathered}
D=\delta \frac{R T}{M} \\
\mu=\frac{D_{a}}{D}
\end{gathered}
$$

where $R\left(\mathrm{~J} \cdot \mathrm{K}^{-1} \cdot \mathrm{mol}^{-1}\right)$ is the universal gas constant, $M$ $\left(\mathrm{kg} \cdot \mathrm{mol}^{-1}\right)$ the molar mass of water, $\mathrm{T}(K)$ the absolute temperature, and $D_{\mathrm{a}}\left(\mathrm{m}^{2} \cdot \mathrm{s}^{-1}\right)$ the diffusion coefficient of water vapor in the air.

The apparent moisture diffusivity determination based on the water sorptivity was determined from samples proof insulated on four lateral sides. Then, the samples were immersed 1-2 $\mathrm{mm}$ under the water, where the level of water was kept constant by a Marriotte's bottle with two capillary tubes. The changes in samples mass were continuously monitored by automatic balance and the water absorption coefficient $\mathrm{A}\left(\mathrm{kg} \cdot \mathrm{m}^{-2} \cdot \mathrm{s}^{-1 / 2}\right)$ was thus calculated as

$$
A=\frac{i}{\sqrt{t}}
$$

where $i\left(\mathrm{~kg} \cdot \mathrm{m}^{-2}\right)$ is the cumulative water absorption and $t$ (s) the time from the beginning of the mass measurement. The apparent moisture diffusivity $\kappa_{\text {app }}$ $\left(\mathrm{m}^{2} / \mathrm{s}\right)$ was calculated using the data revealed from the water absorption coefficient determination and vacuum saturation moisture content, according to the basic formula given in Kumaran [15]

$$
\kappa_{\text {app }}=\left(\frac{A}{w_{\text {sat }}-w_{0}}\right)^{2}
$$

where $w_{\text {sat }}\left(\mathrm{kg} \cdot \mathrm{m}^{-3}\right)$ is the saturated moisture content and $w_{0}\left(\mathrm{~kg} \cdot \mathrm{m}^{-3}\right)$ the initial moisture content.

The sorption and desorption isotherms were obtained by using the desiccator method. In this measurement, the samples were placed into the desiccators with various salt solutions to simulate different values of relative humidity required to the material description. The experiment started with a dry sample simultaneously in several desiccators, while the mass of samples was measured in specified periods until steady-state values of mass were achieved. Afterward, the moisture content $w$ $\left(\mathrm{m}^{3} \cdot \mathrm{m}^{-3}\right)$ was calculated and the $w=w(R H)$ function, i.e. the sorption isotherm, was constructed [16].

Summarized results obtained from the experimental analysis are given in Table 1 . Such data were consequently used as input parameters for computational modeling. Particular mixtures were denoted as RP (reference plaster), PSA0.5 - 1.5 (plaster modified by 0.5 -1.5 wt. $\%$ of SAP).

Table 1. Functional parameters of used materials

\begin{tabular}{lcccc}
\hline Parameter & RP & PSA0.5 & PSA1 & PSA1.5 \\
\hline$\rho_{\mathrm{v}}\left(\mathrm{kg} \cdot \mathrm{m}^{-3}\right)$ & 1597 & 1482 & 1420 & 1284 \\
$\rho_{\text {mat }}\left(\mathrm{kg} \cdot \mathrm{m}^{-3}\right)$ & 2574 & 2557 & 2541 & 2550 \\
$\psi(-)$ & 0.37 & 0.42 & 0.44 & 0.49 \\
$\lambda_{\text {dry }}\left(\mathrm{W} \cdot \mathrm{m}^{-1} \cdot \mathrm{K}^{-1}\right)$ & 0.65 & 0.58 & 0.53 & 0.45 \\
$c_{\text {dry }}\left(\mathrm{J} \cdot \mathrm{kg}^{-1} \cdot \mathrm{K}^{-1}\right)$ & 896 & 933 & 900 & 878 \\
$\mu(-)$ & 15.8 & 14.3 & 12.3 & 9.4 \\
$\kappa_{\text {app }}\left(\mathrm{m}^{2} \cdot \mathrm{s}^{-1}\right)$ & $1.6 \mathrm{E}-8$ & $2.9 \mathrm{E}-8$ & $2.9 \mathrm{E}-7$ & $5.7 \mathrm{E}-7$ \\
\hline
\end{tabular}

\subsection{Computation modeling}

The investigation of heat and moisture transport was performed using the Finite Element Method (FEM) approach using the computational solver SIFEL [17]. This solver is based on the modified Künzel's mathematical model [18] and used to describe heat and moisture transport in the multi-component porous material systems [19]. The original Künzel's model became very popular among building physicists due to 
its simplicity and high level of accuracy [20]. However, the original form of the model contains also several weak points which might lead to possible inaccuracies in obtained outputs. In order to provide more coherent and precise results, two modifications to the regularly used implementations of Künzel's model were applied. The motivation for the modification was driven by the need for an improvement of the model accuracy, numerical stability and for reduction of the computation time. First, contrary to the original form of the model, the relative humidity was replaced by the partial pressure of water vapor $p_{\mathrm{v}}$. Consequently, the integral two-phase formulation of the moisture mass balance equation was modified to better distinguish the particular phases of water [21]. The heat and moisture mass balance equations for one-dimensional transport was modified as follows

$$
\begin{array}{r}
\frac{\mathrm{d} H}{\mathrm{~d} T} \frac{\partial T}{\partial t}=\operatorname{div}(\lambda \operatorname{grad} T)+L_{\mathrm{v}} \operatorname{div}\left(\delta_{\mathrm{p}} \operatorname{grad} p_{\mathrm{v}}\right) \\
{\left[\rho_{w} \frac{d w}{d p_{v}}+(n-w) \frac{M}{R T}\right] \frac{\partial p_{v}}{\partial t}=\operatorname{div}\left[D_{g} \operatorname{grad} p_{v}\right]}
\end{array}
$$

where $H\left(\mathrm{~J} \cdot \mathrm{m}^{-3}\right)$ is the enthalpy density, $T(\mathrm{~K})$ the absolute temperature, $\lambda\left(\mathrm{W} \cdot \mathrm{m}^{-1} \cdot \mathrm{K}^{-1}\right)$ the thermal conductivity, $L_{\mathrm{v}}\left(\mathrm{J} \cdot \mathrm{kg}^{-1}\right)$ latent heat of evaporation of water, $\delta_{\mathrm{p}}(\mathrm{s})$ the water vapor diffusion permeability, $p_{\mathrm{v}}$ (Pa) the partial pressure of water vapor in the porous space, $\rho_{\mathrm{w}}\left(\mathrm{kg} \cdot \mathrm{m}^{-3}\right)$ the density of water, $w\left(\mathrm{~m}^{3} \cdot \mathrm{m}^{-3}\right)$ the moisture content by volume, $n(-)$ the porosity of the porous body, $M\left(\mathrm{~kg} \cdot \mathrm{mol}^{-1}\right)$ the molar mass of water vapor, and $R\left(\mathrm{~J} \cdot \mathrm{K}^{-1} \cdot \mathrm{mol}^{-1}\right)$ is the universal gas constant. $D_{\mathrm{g}}(\mathrm{s})$ is the global moisture transport function defined as

$$
D_{g}=B \cdot D_{w} \rho_{w} \frac{d w}{d p_{v}}+A \cdot \delta_{p}
$$

where $A$ and $B$ are the membership functions defining the transition between particular phases of water. After an analysis of several suitable transition functions which could describe reliably the ratio between the particular phases of water, the coefficients A and B were formulated as

$$
B= \begin{cases}0 & \phi \in\langle 0 ; 0.9) \\ 32\left[\left(\frac{1}{p_{v 2}-p_{v 1}}\right)\left(p_{v}-p_{v 1}\right)\right]^{6} & \phi \in\langle 0.9 ; 0.938) \\ 1-32\left[\left(\frac{1}{p_{v 2}-p_{v 1}}\right)\left(p_{v 2}-p_{v}\right)\right]^{6} & \phi \in\langle 0.938 ; 0.976) \\ 1 & \phi \in\langle 0.976 ; 1\rangle\end{cases}
$$

$$
A=1-B
$$

where the partial pressures of water vapor $p_{\mathrm{v} 1}$ and $p_{\mathrm{v} 2}$ (Pa) define the transition region; they corresponded to values of the relative humidity of $90 \%$ and $97.6 \%$, respectively.

The main aim of the model is paid on the simulation of hygrothermal performance of building materials, elements or entire structures under real climatic loads. For such purpose, one must allow for the possibility of water solidification that may occur during the investigated period as the structure is exposed to the temperatures below the water freezing point. Several approaches offer a solution to this problem as they can describe freeze/thaw processes in porous building materials [22]. Among them, the fixed domain method [23] seems to be most suitable with respect to that applied FEM approach. The fixed-domain method treats both solid and liquid as one continuous medium while interface conditions become implicit in a new form of the equations described for example by enthalpy, specific heat capacity or heat-generation term. The biggest advantage of the fixed-domain method is the fact that it does not require meshing and can be easily implemented into the existing conduction program [24]. For the case of modified Künzel's mathematical model, the implementation of the water solidification phenomena in the form of a smoothed effective heat capacity model [25] seems to be the most suitable. The demonstration of implementation into modified Künzel's mathematical model has been shown in [26, 27].

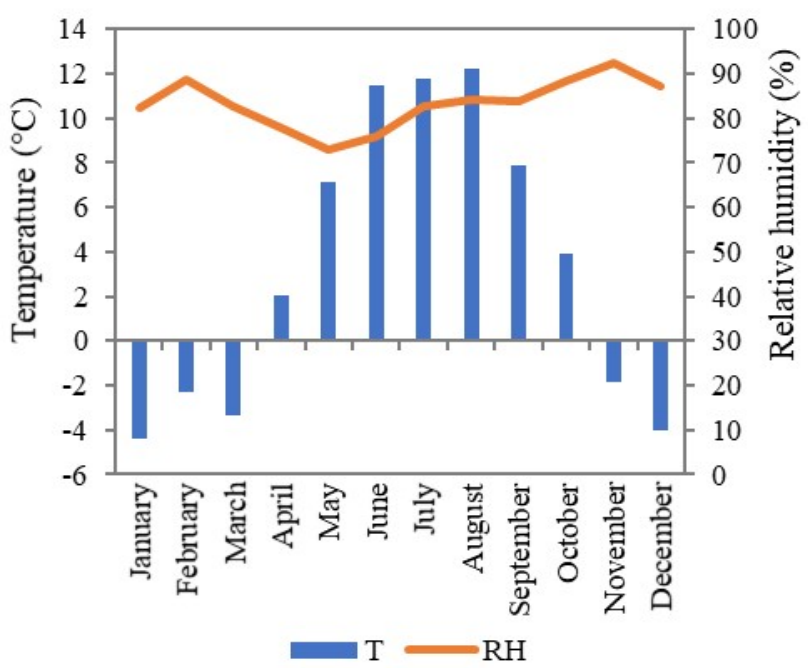

Fig. 3. Exterior variation of temperature and relative humidity

\section{Results and discussion}

The performed computational simulation revealed the hygrothermal performance of the modified plasters and can be deemed as an efficient tool for the determination of the overall performance of the wall assembly.

First, the energy balance was obtained from the calculation of the annual heat fluxes through the wall as is given in Table 2 . 
Table 2. Annual energy savings

\begin{tabular}{lc}
\hline Material & Annual energy savings (\%) \\
\hline RP & 0 \\
PSA0.5 & 1.26 \\
PSA1 & 1.72 \\
PSA1.5 & 3.19 \\
\hline
\end{tabular}

The obtained results revealed only a minor positive effect of the SAP application on the thermal performance of the building envelopes. This effect can be assigned to the changes in the material microstructure, especially the increase in the total open porosity and the consequent reduction in the thermal conductivity. The temperature in the wall cross-section was almost identical and only about $3.2 \%$ of annual energy savings were achieved in the most positive case. Notwithstanding, this improvement can be viewed as side benefit since the applied SAP admixture was used for a passive moderation of the moisture level.

On this account, a distribution of the moisture in the wall cross-section was calculated for particular plaster mixtures to reveal the material performance. In these terms, the effect of used SAP particles was more evident as can be clearly seen in Fig. 4. Here, the level of relative humidity was decreased proportionally to the amount of SAPs, in other words, the highest content of SAPs reduced the humidity level of about $10-12 \%$. The mixtures with a lower content of SAP promoted the reduction of 5-6\% in the case of 0.5 wt. $\%$ SAP and 8-9 $\%$ for plaster with $1 \mathrm{wt} \%$ SAP. The increased moisture accumulation capacity of used SAPs substantially increased the moisture storage, thus reduced moisture transmission to the interior side. The achieved result showed that even a relatively small amount of used SAP can significantly affect the moisture distribution in the building envelope.

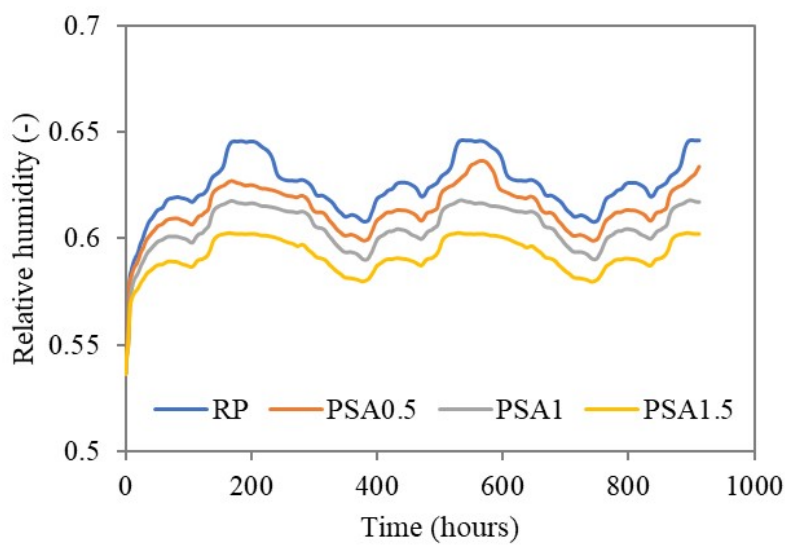

Fig. 4. Variation of relative humidity on the interface between the interior plaster and ceramic brick

The moisture buffering effect can be clearly seen in Figs 5 and 6. Here, the difference in the level of relative humidity in particular plasters is depicted. Both figures reveal a reduction in the moisture distribution in the wall cross-section compared to the reference plaster.
Obtained changes are small, but noticeable and can beneficially contribute to the preservation of the ideal indoor air quality since the increased moisture content provides an ideal environment for mold growth.

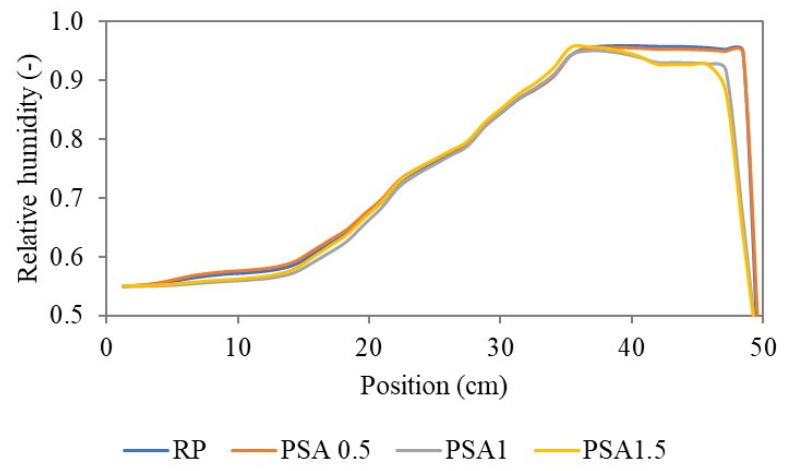

Fig. 5. Distribution of relative humidity in the studied wall on March 1.

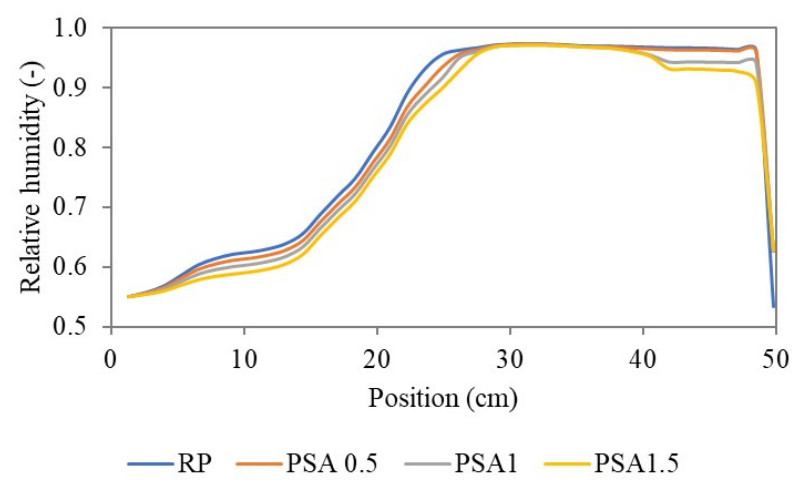

Fig. 6. Distribution of relative humidity in the studied wall on September 1.

\section{Conclusions}

This paper contemplates the utilization of the SAP admixture in plasters as a passive moisture control agent. For this purpose, three plasters with a different SAP content were experimentally analyzed to obtain input parameters for the computational modeling.

In our study, the reference plaster was modified by $0.5,1$ and 1.5 wt.\% of SAP in order to describe the influence of used SAP on the moisture transport and storage properties. Based on the achieved results, the incorporation of the SAP admixture has influenced the moisture transport parameters and modified the distribution of the humidity in the wall cross-section. Notwithstanding, the performed computational analysis revealed only a minor benefit compared to the reference plaster in terms of energy performance. On the other hand, the utilization of SAP was reflected in the reduction in the relative humidity in the building envelope by approximately $6-10 \%$. This finding can be effectively employed in building for the maintenance of the optimal indoor air quality since the level of relative humidity was found as a significant problem of the present buildings due to potential health issues 
associated with mold growth in constructions suffering from external moisture loading.

In other words, the utilization of SAP became an attractive topic for the modification of traditional building materials, thus further and detailed investigation is required for the understanding of the material response, and accompanied consequences.

The authors gratefully acknowledge the financial support received from the Czech Science Foundation under project No. 18-03997S.

\section{References}

1. U. Alev, T. Kalamees, Build. Environ. 105104 (2016)

2. P.J. Annila, J. Lahdensivu, J. Suonketo, M. Pentti, J. Vinha, J. Build. Eng. 16, 72 (2018)

3. R. Bui, M. Labat, S. Lorente, Build. Environ. 160, 12 (2019)

4. T. Busser, M. Pailha, A. Piot, M. Woloszyn, Build. Environ. 148, 677 (2019)

5. V. Cascione, D. Maskell, A. Shea, P. Walker, Constr. Build. Mater. 200, 333 (2019)

6. L. Fang, G. Clausen, P.O. Fanger, Indoor Air 8 (2), 80 (1998)

7. B. Koelblen, A. Psikuta, A. Bogdan, S. Annaheim, R.M. Rossi, Indoor Air 27 (3), 680 (2017)

8. D.Y. Kong, H. Liu, Y.X. Wu, B.Z. Li, S. Wei, M.W. Yuan, Build. Environ. 155, 298 (2019)

9. H. Goncalves, B. Goncalves, L. Silva, NVieira, F. Raupp-Pereira, L. Senff, J.A. Labrincha, Energ. Buildings 74, 61 (2014)

10. L. Senff, R.C.E. Modolo, G. Ascensao, D. Hotza, V.M. Ferreira, J.A. Labrincha, Constr. Build. Mater. 95, 575 (2015)

11. J.M. Macher, M.J. Mendell, W. Chen, K. Kumagai, Indoor Air 27 (3), 599 (2017)

12. F. McGregor, A. Heath, A. Shea, M. Lawrence, Build. Environ. 82, 599 (2014)

13. J.M. Macher, M.J. Mendell, W. Chen, K. Kumagai, Indoor Air 28 (4), 488 (2018)

14. X.G. Xu, Z.W. Zhong, S.M. Deng, X.B. Zhang, Energ. Buildings 162, 163 (2018)

15. M.K. Kumaran, J. Therm. Env. Build. Sci. 22, 349 (1999)

16. S. Roels, J. Carmeliet, H. Hens, O. Adan, H. Brocken, R. Černý, J. Therm. Env. Build. Sci. 27, 253 (2004)

17. V. Kočí, J. Maděra, R. Černý, Energ. Buildings 47, 84-90 (2012)

18. J. Kočí, J. Maděra, J. Fořt, AIP 2186, 070010 (2019)

19. M. Čáchová, D. Koňáková, E. Vejmelková, M. Keppert, K. Polozhiy, R. Černý, R. AMR 982, 104 (2014)

20. J. Kruis, T. Koudelka, T. Krejci, Math. Comput. Simulat. 80 (8), 1578 (2010).
21. V. Kočí, J. Kočí, J. Maděra, Z. Pavlík, X. Gu, W. Zhang, R. Černý, J. Build. Phys. 41(6), 497 (2018)

22. I. Otmen, P. Poullain, A. Caucheteux, N. Leklou, Trans.Eng. Sci 83, 417 (2014)

23. Z. Pavlík, J. Kočí, M. Pavlíková, R. Černý, Int. J. Chem. Eng. 6, 127 (2012)

24. J. Crank, Clarendon Press, Oxford (1984)

25. R.W. Lewis, K. Ravindran, Int. J. Num. Meth. Eng. 47, 29 (2000)

26. H. Yang, Y. He, Int Com. H. Mass 37, 385 (2010)

27. V. Kočí, R. Černý, AIP 1752, 040013 (2016) 